\title{
Cross-sectional scanning tunneling microscopy of InAsSb/InAsP superlattices
}

\author{
S. L. Zuo and E. T. Yu ${ }^{\mathrm{a}}$ \\ Department of Electrical and Computer Engineering \\ University of California at San Diego \\ La Jolla, California 92093-0407 \\ A. A. Allerman and R. M. Biefeld \\ Sandia National Laboratories \\ Albuquerque, New Mexico 87185-0601 \\ ABSTRACT

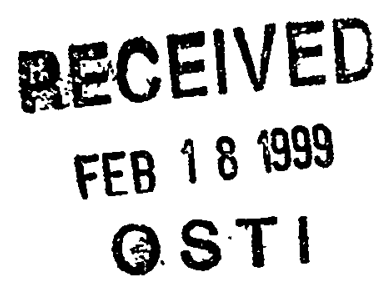

Cross-sectional scanning tunneling microscopy has been used to characterize compositional structure in InAs ${ }_{0.87} \mathrm{Sb}_{0.13} / \mathrm{InAs}_{0.73} \mathrm{P}_{0.27}$ and InAs ${ }_{0.83} \mathrm{Sb}_{0.17} / \mathrm{InAs}_{0.60} \mathrm{P}_{0.40}$ strainedlayer superlattice structures grown by metal-organic chemical vapor deposition. Highresolution STM images of the (110) cross section reveal compositional features within both the InAs $S_{x} b_{1-x}$ and InAs $P_{1-y}$ alloy layers oriented along the [ $\left.\overline{1} 12\right]$ and [1 12$]$ directions - the same as those in which features would be observed for CuPt-B type ordered alloys. Typically one variant dominates in a given area, although occasionally the coexistence of both variants is observed. Furthermore, such features in the alloy layers appear to be correlated across heterojunction interfaces in a manner that provides support for III-V alloy ordering models which suggest that compositional order can arise from strain-induced order near the surface of an epitaxially growing crystal. Finally, atomically resolved $(1 \overline{1} 0)$ images obtained from the $\operatorname{InAs}_{0.87} \mathrm{Sb}_{0.13} / \operatorname{InAs}{ }_{0.73} \mathrm{P}_{0.27}$ sample reveal compositional features in the [112] and [ $\overline{1} \overline{1} 2]$ directions, i.e., those in which features would be observed for CuPt-A type ordering.

a) Electronic mail: ety@ece.ucsd.edu 


\section{DISCLAIMER}

This report was prepared as an account of work sponsored by an agency of the United States Government. Neither the United States Government nor any agency thereof, nor any of their employees, make any warranty, express or implied, or assumes any legal liability or responsibility for the accuracy, completeness, or usefulness of any information, apparatus, product, or process disclosed, or represents that its use would not infringe privately owned rights. Reference herein to any specific commercial product, process, or service by trade name, trademark, manufacturer, or otherwise does not necessarily constitute or imply its endorsement, recommendation, or favoring by the United States Government or any agency thereof. The views and opinions of authors expressed herein do not necessarily state or reflect those of the United States Government or any agency thereof. 


\section{DISCLAIMER}

Portions of this document may be illegible in electronic image products. Images are produced from the best available original document. 


\section{INTRODUCTION}

Mid- to long-wavelength infrared emitters and detectors are of great importance for applications such as chemical sensing, fiber communication, molecular spectroscopy, and infrared detection. InAs $S_{x} b_{1-x}$-based alloys and superlattices have shown great promise for mid- to long-wavelength infrared devices operating at wavelengths from 2$12 \mu \mathrm{m} .{ }^{1.2}$ These materials are of particular interest because in narrow band gap materials, the threshold energy for Auger processes, which frequently suppress the radiating recombination, ${ }^{3}$ is reduced and the wavelength at which emitters operate at room temperature is therefore typically limited to $\sim 2.1-2.3 \mu \mathrm{m}^{4}{ }^{4}$ For $\operatorname{InAs}_{x} \mathrm{Sb}_{1 . x}$-based materials grown on $\mathrm{GaSb}$ or InAs substrates, the compressive strain in the $\operatorname{InAs_{x}} \mathrm{Sb}_{t-x}$ layer will facilitate population inversion in laser structures ${ }^{5}$ and will suppress Auger processes by decreasing the hole effective mass and increasing the Auger process threshold energy. ${ }^{3}$ In addition, InAs $\mathrm{Sb}_{1-x} / \operatorname{InAs}_{y} \mathrm{P}_{1-y}$ heterostructures have been of considerable recent interest for such applications, because the enhanced valence-band offset improves the heavy-light hole splitting within the compressively strained $\operatorname{InAs} \mathrm{Sb}_{\mathrm{l}-\mathrm{x}}$ layer, further suppressing Auger processes. ${ }^{6}$ Crystal quality is also expected to be improved due to strain compensation.

For a variety of ternary and quaternary III-V alloys, features in compositional structure such as ordering, clustering, phase separation, and spontaneous compositional modulation have been observed to occur. ${ }^{7-10}$ Such features may significantly influence material properties such as band gap, ${ }^{11}$ interface quality, carrier mobility, or luminescence spectra. ${ }^{12-15}$ Indeed, partial CuPt-B type ordering has been observed to occur, and to lead to a reduction in band gap, within $\operatorname{InAs}_{x} \mathrm{Sb}_{1-\mathrm{x}}$ alloys for $\mathrm{Sb}$ compositions as low as $x \approx 0.07$ $0.14 .^{2.10}$ In In $\mathrm{As}_{x} \mathrm{Sb}_{1-x}$ alloys, ordering-induced band gap narrowing can extend the useful photoresponse to $8-12 \mu \mathrm{m}$, corresponding to band gaps as small as $\sim 100 \mathrm{meV}$, much smaller than expected for random alloys. ${ }^{16}$ The existence of similar compositional structure, and its precise nature, within $\operatorname{InAs}_{x} \mathrm{Sb}_{1-x} / \operatorname{InAs}_{y} P_{1-y}$ superlattices, and especially within the InAs $\mathrm{Sb}_{\mathrm{x}-\mathrm{x}}$ layer, may significantly influence material and device properties. A detailed understanding of the atomic-scale compositional structure within such 
heterostructures is therefore essential for optimization of material properties and device performance.

In this paper, we describe ultrahigh-vacuum cross-sectional scanning tunneling microscopy (STM) studies of pseudomorphic InAs $\mathrm{Sb}_{1-x} / \ln A s_{y} P_{1-y}$ strained-layer superlattices (SLS) grown on InAs (001) substrates. Details concerning the experiments and sample structures will be discussed in Section II. High-resolution STM images obtained from both cross-sections of $\operatorname{InAs} \mathrm{Sb}_{\mathrm{x}-\mathrm{x}} / \mathrm{InAs}_{\mathrm{y}} \mathrm{P}_{\mathrm{l}-\mathrm{y}} \mathrm{SLS}$ samples revealing features in compositional structure with orientation similar to that observed in both $\mathrm{CuPt}-\mathrm{B}$ type and CuPt-A type ordering will be presented in Section III. Furthermore, compositional features with similar local strain relative to that in the surrounding material are observed to be correlated across the heterojunction interfaces, suggesting that strain play a very important role in the determination of compositional structure in these materials. Section IV concludes the paper.

\section{EXPERIMENT}

The InAs $\mathrm{Sb}_{\mathrm{l}-\mathrm{x}} / \mathrm{InAs} \mathrm{P}_{\mathrm{y}-\mathrm{y}}$ multiple-quantum-well (MQW) samples used in these studies were grown by metal-organic chemical vapor deposition (MOCVD). The growth temperature was $500^{\circ} \mathrm{C}$ and the growth rate was $2.5 \AA / s$; additional details concerning the growth apparatus and procedures are described elsewhere. ${ }^{6.17}$ Figure 1 shows a schematic illustration of the sample structure and STM geometry. For each sample, a $500 \AA$ InAs buffer layer was grown initially on $n$-type InAs (001) substrates, followed by a ten-period InAs $s_{x} \mathrm{Sb}_{1-x} / \mathrm{InAs}_{y} \mathrm{P}_{1-y} \mathrm{MQW}$ structure, and finally another InAs $\mathrm{P}_{1-y}$ layer. Here we present results obtained from two samples - a $65 \AA$ In $\mathrm{As}_{0.87} \mathrm{Sb}_{0.13} / 90 \AA \operatorname{InAs} \mathrm{s}_{0.73} \mathrm{P}_{0.27} \mathrm{MQW}$ structure sample, and a $110 \AA \operatorname{InAs}_{0.83} \mathrm{Sb}_{0.17} / 112 \AA$ InAs $\mathrm{s}_{0.6} \mathrm{P}_{0.4} \mathrm{MQW}$ structure sample. STM studies were performed on both (110) and $(1 \overline{10})$ cross-sectional surfaces exposed by in situ cleaving in an ultrahigh-vacuum (UHV) STM chamber at a pressure of $\sim 7 \times 10^{-11}$ Torr. Electrochemically etched W tips and commercially available Pt/Ir tips cleaned in situ by electron bombardment were used for these studies. 


\section{RESULTS AND DISCUSSION}

Figure 2(a) shows a three-dimensional rendering of a $210 \AA \times 210 \AA$ filled-state (110) constant-current STM image of the $65 \AA \operatorname{InAs} s_{0.87} \mathrm{Sb}_{0.13} / 90 \AA \operatorname{InAs} s_{0.73} \mathrm{P}_{0.27}$ multiple quantum well structure, obtained at a sample bias of $-1.6 \mathrm{~V}$ and a tunneling current of $0.1 n A$. The InAs $\mathrm{Sb}_{1-x}$ layer appears brighter (higher topographically), while the $\operatorname{In} \mathrm{As}_{\mathrm{y}} \mathrm{P}_{1-\mathrm{y}}$ layer appears darker (lower topographically), with a typical topographic contrast of $\sim 2$ $2.5 \AA$ between the two layers. The topographic contrast observed between the $\operatorname{In} A s_{x} S_{1-x}$ and $\operatorname{InAs}_{y} \mathrm{P}_{\text {l.y }}$ layers can arise from two sources. First, the valence-band edge of $\operatorname{In} A s_{0.87} \mathrm{Sb}_{0.13}$ is higher than that of InAs $\mathrm{s}_{0.73} \mathrm{P}_{0.27}$, leading to a larger tip-sample separation, i.e., greater topographic height, in the $\operatorname{InAs_{x}} S_{1-x}$ layer in a filled-state constant current STM image. Second, the compressive and tensile strain in the $\operatorname{InAs_{x}} S_{t-x}$ and $\operatorname{InAs_{y}} P_{1-y}$ layers, respectively, will lead to actual topographic variation on the cleaved surface. The compressively strained InAs $\mathrm{Sb}_{\mathrm{i}-\mathrm{x}}$ layer will protrude slightly, while the $\operatorname{InAs_{y}} \mathrm{P}_{1-y}$ layer, which is under tensile strain, will be slightly depressed. These morphological variations will also cause the $\operatorname{In} A s_{x} S_{1}$ l-x layer to appear higher and the $\operatorname{InAs} \mathrm{P}_{1-y}$ layer to appear lower topographically. A simple calculation based on elasticity theory ${ }^{18.19}$ indicates that the amplitude of these undulations should not exceed a few tenths of an angstrom; the contrast between the InAs $\mathrm{s}_{0.77} \mathrm{Sb}_{0.13}$ and $\operatorname{InAs} \mathrm{s}_{0.73} \mathrm{P}_{0.27}$ layers therefore appears to be primarily electronically induced.

In addition to the overall contrast between different layers, detailed variations in contrast corresponding to local variations in electronic and, by extension, compositional structure are clearly visible. Specifically, compositional features aligned along the $<112>$ directions in both the $\operatorname{In} \mathrm{As}_{\mathrm{x}} \mathrm{Sb}_{1-x}$ and $\operatorname{InAs_{y}\mathrm {P}_{1-y}}$ layers are clearly seen. In Fig. 2(a), compositional features along the [ $\overline{1} 12]$ direction in the (110) plane (perpendicular to the [1 111$]$ direction in the crystal), are clearly visible in both the $\operatorname{InAs}_{0.73} \mathrm{P}_{0.27}$ and $\operatorname{InAs} s_{0.87} \mathrm{Sb}_{0.13}$ alloy layers. These $[\overline{1} 12]$ features are associated with compositional variations along the [1 $1 \overline{1} 1]$ direction in the crystal. In CuPt-B type ordering, the type most commonly observed in III-V zincblende semiconductors, the composition is periodic with a period of $2 a / \sqrt{3}$ (where $a$ is the cubic lattis constant) along the $[\overline{1} 11]$ and $[1 \overline{1} 1]$ directions in the 
crystal. The features seen in Fig. 2(a) are therefore reminiscent of those associated with the (1 $\overline{1} 1)$ variant of CuPt-B type ordering. However, the compositional structure observed does not correspond to actual CuPt-B type ordering, for which the periodicity in the $[1 \overline{1} 1]$ direction would be only $\sim 7 \AA$. The observation of compositional variations along only the [1 $\overline{1} 1]$ direction is most likely a local characteristic of the area imaged by $\mathrm{STM}$, as previous studies of $\operatorname{InAs}_{x} \mathrm{Sb}_{1-x}$ alloys have shown that CuPt-B type ordering can occur in these materials with local variations present in the relative intensities of the $(\overline{1} 11)$ and $(1 \overline{1} 1)$ variants. ${ }^{10}$

Closer examination of the STM image reveals that compositional structure in the alloy layers appears to be correlated across heterojunction interfaces. Specifically, dark regions in the InAs $\mathrm{P}_{1-y}$ layer in Fig. 2(a) appear to extend across the heterojunction interfaces in the $[\overline{1} 12]$ direction and merge with dark regions in the $\operatorname{InAs}_{x} S b_{1-x}$ alloy. In the InAs $\mathrm{Sb}_{\mathrm{x}-\mathrm{x}}$ alloy, increasing the $\mathrm{Sb}$ concentration will cause the valence-band edge to move higher in energy and the degree of compressive strain to increase, while in the InAs $P_{\mathrm{L}-\mathrm{y}}$ alloy, increasing the $\mathrm{P}$ concentration will cause the valence-band edge to move lower and the degree of tensile strain to increase. The areas of dark contrast in the InAs $\mathrm{P}_{\mathrm{I}-\mathrm{y}}$ layer, therefore, correspond unambiguously to regions of P-rich composition, with greater tensile strain than the surrounding alloy, while those in the $\operatorname{InAs}_{x} \mathrm{Sb}_{1-x}$ layer correspond to As-rich regions, with less compressive strain relative to the surrounding material. The alignment of $\mathrm{P}$-rich regions in the $\operatorname{InAs_{y}} \mathrm{P}_{1-y}$ layer with As-rich regions in the InAs $\mathrm{Sb}_{\mathrm{k}-\mathrm{x}}$ layer observed in the image therefore corresponds to an alignment within (1 $\overline{1} 1)$ planes across heterojunction interfaces of regions with a smaller average lattice constant than the surrounding material.

Fig. 2(b) shows a three-dimensional rendering of a $230 \AA ̊ \times 230 \AA$ filled-state (110) constant-current STM image of the $110 \AA \operatorname{InAs} s_{0.83} \mathrm{Sb}_{0.17} / 112 \AA \operatorname{In} A s_{0.60} \mathrm{P}_{0.40}$ multiplequantum-well structure, obtained at a sample bias of $-1.8 \mathrm{~V}$ and a tunneling current of $0.1 \mathrm{nA}$. In this image, compositional features aligned along the [ $\overline{1} 12]$ and [1 $\overline{1} 2]$ directions are visible in both the $\operatorname{In} A s_{0.83} \mathrm{Sb}_{0.17}$ and $\operatorname{In} \mathrm{As}_{0.00} \mathrm{P}_{0.40}$ layers. Unlike the region 
shown in Fig. 2(a), where compositional variation is observed predominantly along the [1 $\overline{1} 1]$ direction, features corresponding to compositional variation in both the [ $\overline{1} 11]$ and [1 111$]$ directions are observed to coexist in this image. On the basis of previous transmission electron diffraction studies of $\operatorname{InAs}_{x} \mathrm{Sb}_{1-x}$ alloy ordering in which the relative intensities of CuPt-B type ordering variants were found to vary with location in the sample, ${ }^{10}$ we believe that observations of compositional features along both the [ $\left.\overline{1} 11\right]$ and $[1 \overline{1} 1]$ directions or of compositional features along only one of these directions in different images reflect local variations within a given sample, rather than systematic differences between samples.

Fig. 2(b) also reveals the presence of correlations of compositional features across the heterojunction interfaces similar to those seen in Fig. 2(a). As with the previous sample, increasing the $\mathrm{Sb}$ concentration in the $\operatorname{InAs}_{x} \mathrm{Sb}_{1-x}$ alloy will cause the valenceband edge to move higher in energy and the degree of compressive strain to increase, while increasing the $\mathrm{P}$ concentration in the $\operatorname{InAs_{y}} \mathrm{P}_{1-\mathrm{y}}$ alloy will cause the valence-band edge to move lower and the degree of tensile strain to increase. Darker features in both the InAs $\mathrm{Sb}_{1-x}$ and InAs $\mathrm{P}_{\mathrm{y}-\mathrm{y}}$ layers are therefore associated with an average lattice constant smaller than that in the surrounding material, while brighter features are associated with a larger average lattice constant. The observation in both samples studied of correlation across heterojunction interfaces of regions with similar strain relative to the surrounding material suggests that local strain is a significant factor in determination of compositional structure in these materials. Theoretical models of ordering in III-V alloys have suggested that alloy ordering arises from strain-induced order in surface reconstructions present during growth that is subsequently incorporated into the structure of the epitaxially grown alloy. ${ }^{20-22}$ Our observations described above are consistent with such models of ordering during epitaxial growth, and further suggest that, to some degree, such ordering can propagate across heterojunction interfaces.

We have also obtained STM images of the $(1 \overline{1} 0)$ cross-sectional surface for the $65 \AA \operatorname{InAs}_{0.87} \mathrm{Sb}_{0.13} / 90 \AA \operatorname{InAs}_{0.73} \mathrm{P}_{0.27}$ multiple-quantum-well sample. These images provide 
additional information about compositional structure within the group V sublattice. Fig. 3(a) shows a three-dimensional rendering of an atomically resolved (1 $\overline{1} 0)$ filled-state STM image obtained at a sample bias of $-1.65 \mathrm{~V}$ and a tunneling current of $0.1 \mathrm{nA}$. From this image we see that features oriented along the [112] and [ $\overline{1} 12]$ directions are present within the $\operatorname{In} \mathrm{As}_{\mathrm{x}} \mathrm{Sb}_{\mathrm{l}-\mathrm{x}}$ layer. Such features correspond to compositional variation along the [11 $\overline{1}]$ and [111]directions, respectively, the same as those in which compositional variations occur for CuPt-A type ordering, which is observed much less frequently than CuPt-B type ordering. ${ }^{22.23}$

The resolution attained in this image is sufficient for more detailed investigations of compositional structure on the exposed ( $1 \overline{1} 0$ ) surface, which reveal nanoscale regions within the alloy in which strong CuPt-A type ordering appears to occur. In the magnified view of the InAs $\mathrm{Sb}_{1-x}$ layer shown in Fig. 3(a), a compositional feature aligned in the [ $\overline{1} \overline{1} 2]$ direction is indicated. The bright and dark atoms in the image correspond to $\mathrm{Sb}$ and As, respectively. Simple counting yields a composition of approximately In $\mathrm{As}_{0.23} \mathrm{Sb}_{0.77}$ in this region of the alloy. In the magnified view, three arrows indicate the intersections of three adjacent (111) planes in the crystal with the exposed (1 10$)$ crosssectional surface. Fig. 3(b) shows the compositional structure that would correspond to ideal CuPt-A type ordering, with the planes corresponding to those indicated in Fig. 3(a) marked by arrows. In the uppermost plane indicated in Fig. 3(a), six of the seven group $\mathrm{V}$ atoms in the top layer are $\mathrm{Sb}$, with one being undetermined. In the bottom plane indicated in Fig. 3(a), five of the seven group $V$ atoms in the top layer are Sb. In the middle plane, only the rightmost [110] row of atoms in the top layer clearly contains $\mathrm{Sb}$; the remainder appear to be As atoms. For perfect CuPt-A type ordering, the top and bottom planes would contain only $\mathrm{Sb}$, and the middle plane only As. While the group $\mathrm{V}$ composition in the second-layer atomic rows cannot be determined unambiguously from this image, the compositional structure observed in the top-layer rows strongly suggests that the area described above possesses a high degree of the (111) variant of CuPt-A type ordering. Because the average $\mathrm{Sb}$ composition in the alloy is only $\sim 13 \%$, it is not unexpected that only small regions of highly ordered material would be observed. 


\section{CONCLUSION}

Cross-sectional STM has been used to investigate compositional structure in In $\mathrm{As}_{0.87} \mathrm{Sb}_{0.13} / \operatorname{InAs} s_{0.73} \mathrm{P}_{0.27}$ and InAs $\mathrm{Is.83}_{0.17} \mathrm{Sb}_{0.17} / \operatorname{InAs}_{0.00} \mathrm{P}_{0.40}$ strained-layer superlattice samples. Filled-state (110) cross-sectional images of both samples reveal compositional features within both $\operatorname{InAs} \mathrm{Sb}_{1-\mathrm{x}}$ and $\operatorname{In} A s_{y} \mathrm{P}_{1-\mathrm{y}}$ layer with orientations that are the same as those present for CuPt-B type ordering; regions in which compositional variations in both the [ $\overline{1} 11]$ and $[1 \overline{1} 1]$ directions coexist as well as areas in which one orientation dominates are observed. Furthermore, clear evidence is found that certain compositional features are correlated across heterojunction interfaces within the superlattices. Detailed analysis reveals that these compositional features are associated with local strain, suggesting that strain plays a very important role in the determination of compositional structure within these materials. These observations lend support to theories of ordering in epitaxially grown material in which surface reconstructions present during growth induce nearsurface compositional order, which is then incorporated into the epitaxially grown alloy.

Finally, atomically resolved $(1 \overline{1} 0)$ cross-sectional images of an $\operatorname{InAs} s_{0.87} \mathrm{Sb}_{0.13} / \operatorname{InAs} s_{0.73} \mathrm{P}_{0.27}$ multiple-quantum-well sample reveal nanoscale regions in the $\operatorname{InAs_{x}} S_{1-x}$ layer within which the compositional structures appears to possess a high degree of CuPt-A type ordering.

\section{ACKNOWLEDGMENTS}

Part of this work was supported by NSF (ECS 95-07986). E. T. Y. would like to acknowledge financial support from the Alfred P. Sloan Foundation.

Sandia is a multiprogram laboratory operated by Sandia Corporation, a Lockheed Martin Company. for the United States Department of Energy under contract DE-AC04-94AL85000. 


\section{References}

' R. M. Biefeld, A. A. Allerman, and S. R. Kurtz, Mater. Sci. and Engin. B51, 1 (1998).

${ }^{2}$ S. R. Kurtz, L. R. Dawson, R. M. Biefeld, D. M. Follstaedt, and B. L. Doyle, Phys. Rev. B 46, 1909 (1992).

${ }^{3}$ S. R. Kurtz and R. M. Biefeld, Proceedings of Seventh International Conference on Narrow Gap Semiconductors, 1995, Sante Fe, NM, USA, 8-12 Jan. 1995, p.18.

${ }^{4}$ H. K. Choi and S. J. Eglash, Appl. Phys. Lett. 61, 1154 (1992).

${ }^{5}$ E. Yablonovitch and E. O. Kane, J. Lightwave Technol. 6, 1292 (1988).

${ }^{6}$ R. M. Biefeld, A. A. Allerman, S. R. Kurtz, and J. H. Burkhart Compound Semiconductors 1997: Proceedings of the IEEE Twenty Fourth International Symposium on Compound Semiconductors, San Diego, CA, USA, 8-11 Sept. 1997, p.113.

${ }^{7}$ H. R. Jen, D. S. Cao, and G. B. Stringfellow, Appl. Phys. Lett. 54, 1890 (1989).

${ }^{8}$ H. R. Jen, K. Y. Ma, and G. B. Stringfellow, Appl. Phys. Lett. 54, 1154 (1989).

${ }^{9}$ A. Gomyo, T. Suzuki, and S. Iijima, Phys, Rev. Lett. 60, 2645 (1988).

${ }^{10}$ D. M. Follstaedt, R. M. Biefeld, S. R. Kurtz, and K. C. Baucom, J. Electronic Mater., 24, 819 (1995).

${ }^{1}$ K. A. Mäder and A. Zunger, Appl. Phys. Lett. 64, 2882 (1994).

${ }^{12}$ G.B Stringfellow and G. S. Chen, J. Vac. Sci. Technol. B 9, 2182 (1991).

${ }^{13}$ A. Zunger and S. Mahajan, Handbook on Semiconductors, vol. 3B, Materials, Properties and Preparation, edited by S. Mahajan (North-Holland, Netherlands, 1994), pp.1399.

${ }^{14}$ P. K. Bhattacharya and J. W. Ku, J. Appl. Phys. 58, 1410 (1985).

${ }^{15}$ A. Gomyo, T. Suzuki, and S. Tijima, Phys. Rev. Lett. 60 , 2645 (1988).

${ }^{16}$ M. Y. Yen, R. People, K. W. Wecht, and A. Y. Cho, Appl. Phys. Lett. 52, 489 (1988).

${ }^{17}$ R. M. Biefeld, K. C. Baucom, and S. R. Kurtz, J. of Crystal Growth, 137, 231 (1994).

${ }^{18}$ e. g., L. D. Landau and E. M. Lifshitz, Theory of Elasticity, (Pergamon Press, London, 1959) 
${ }^{19}$ H. Chen, R. M. Feenstra, R. S. Goldman, C. Silfvenius, and G. Landgren, Appl. Phys. Lett. 72, 1727 (1998).

${ }^{20}$ S. Froyen and A. Zunger, Phys. Rev. Lett. 66, 2132 (1991).

${ }^{21}$ S. Froyen and A. Zunger, Phys. Rev. B 66, 4570 (1996).

${ }^{22}$ S. B. Zhang, S. Froyen, and A. Zunger, Appl. Phys. Lett. 67, 3141 (1995).

${ }^{23}$ T. Suzuki, T. Ichihashi, and T. Nakayama, Appl. Phys. Lett. 73, 2588 (1998). 


\section{Figure Captions.}

FIG. 1. Schematic diagram of the sample structure and STM geometry used in these studies. Samples consist of a $500 \AA$ InAs buffer layer grown on an $n$-type InAs (001) substrate, followed by a ten-period InAs $\mathrm{Sb}_{\mathrm{x}-\mathrm{x}} / \mathrm{InAs} \mathrm{s}_{\mathrm{y}} \mathrm{P}_{1-\mathrm{y}}$ multiple-quantum-well structure capped by a final InAs $\mathrm{P}_{1-\mathrm{y}}$ layer.

FIG. 2 (a). Three-dimensional rendering of a $210 \AA \times 210 \AA$ (110) constant-current STM image of the InAs${ }_{0.87} \mathrm{Sb}_{0.13} / \operatorname{InAs} s_{0.73} \mathrm{P}_{0.27}$ multiple-quantum-well structure, obtained at a sample bias voltage of $-1.6 \mathrm{~V}$ and a tunneling current of $0.1 \mathrm{nA}$. [ $\overline{1} 12]$ compositional features correlated across heterojunction interfaces are marked by arrows. (b). Threedimensional rendering of a $230 \AA \times 230 \AA$ constant-current (110) STM image of the $\operatorname{InAs}_{0.83} \mathrm{Sb}_{0.17} / \mathrm{InAs}_{0.60} \mathrm{P}_{0.40}$ multiple-quantum-well structure, obtained at a sample bias voltage of $-1.8 \mathrm{~V}$ and a tunneling current of $0.1 \mathrm{nA}$. [ [ $\overline{1} 12]$ and [1 $\overline{1} 2]$ compositional features correlated across heterojunction interfaces are marked by arrows.

FIG. 3 (a). Three-dimensional rendering of a constant-current (1 $\overline{1} 0)$ STM image of an InAs $s_{0.87} \mathrm{Sb}_{0.13}$ layer within the InAs$s_{0.87} \mathrm{Sb}_{0.13} / \operatorname{InAs}_{0.73} \mathrm{P}_{0.27}$ superlattice, obtained at a sample bias voltage of $-1.65 \mathrm{~V}$ and a tunneling current of $0.1 \mathrm{nA}$. Compositional features aligned in the [112] and [ $\overline{1} \overline{1} 2]$ directions are delineated by dotted lines. The magnified view at right contains an area with a high degree of CuPt-A type ordering. (b) Schematic illustration of the (111) variant of perfect CuPt-A type ordering in $\operatorname{InAs}_{\mathbf{x}} \mathrm{Sb}_{1-\mathrm{x}}$. 


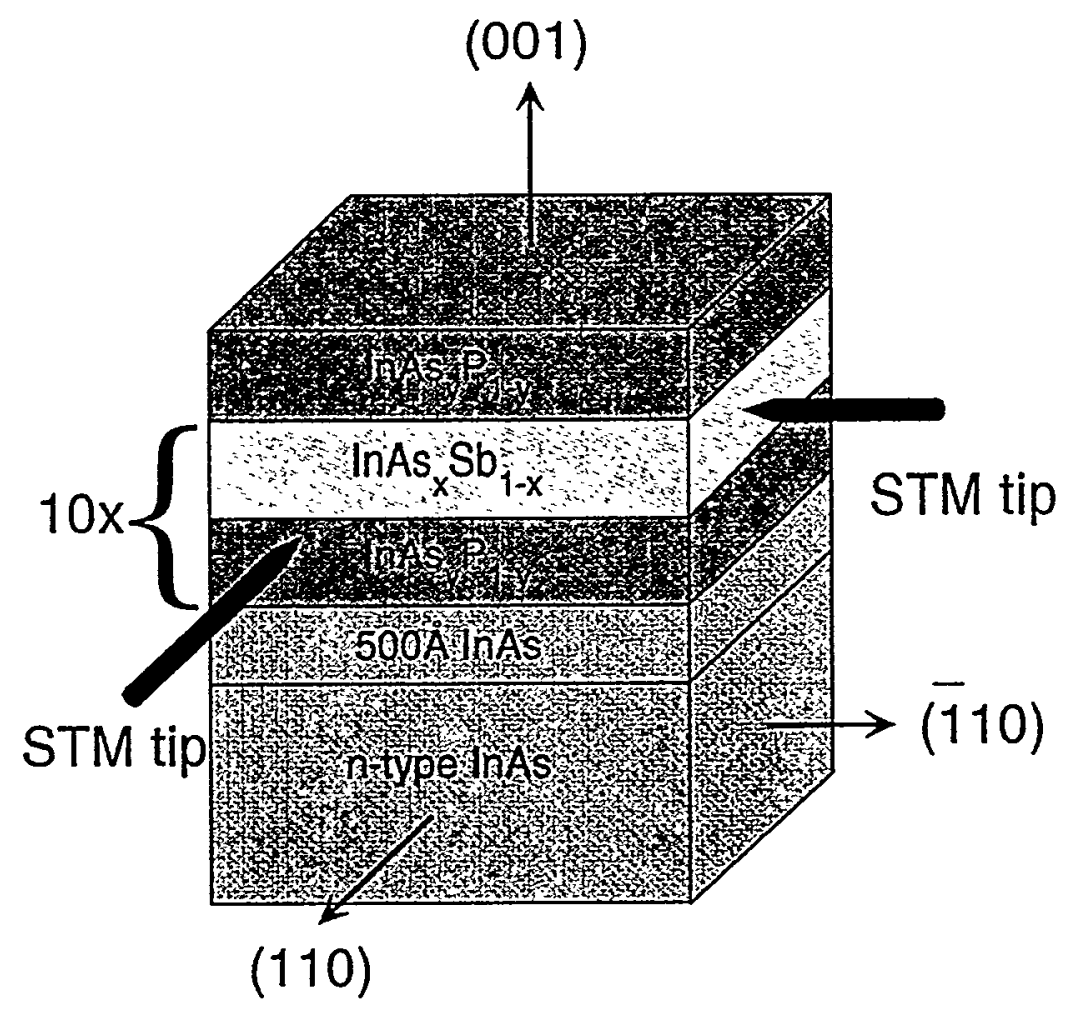

Figure 1

S. L. Zuo et al. 
(a)

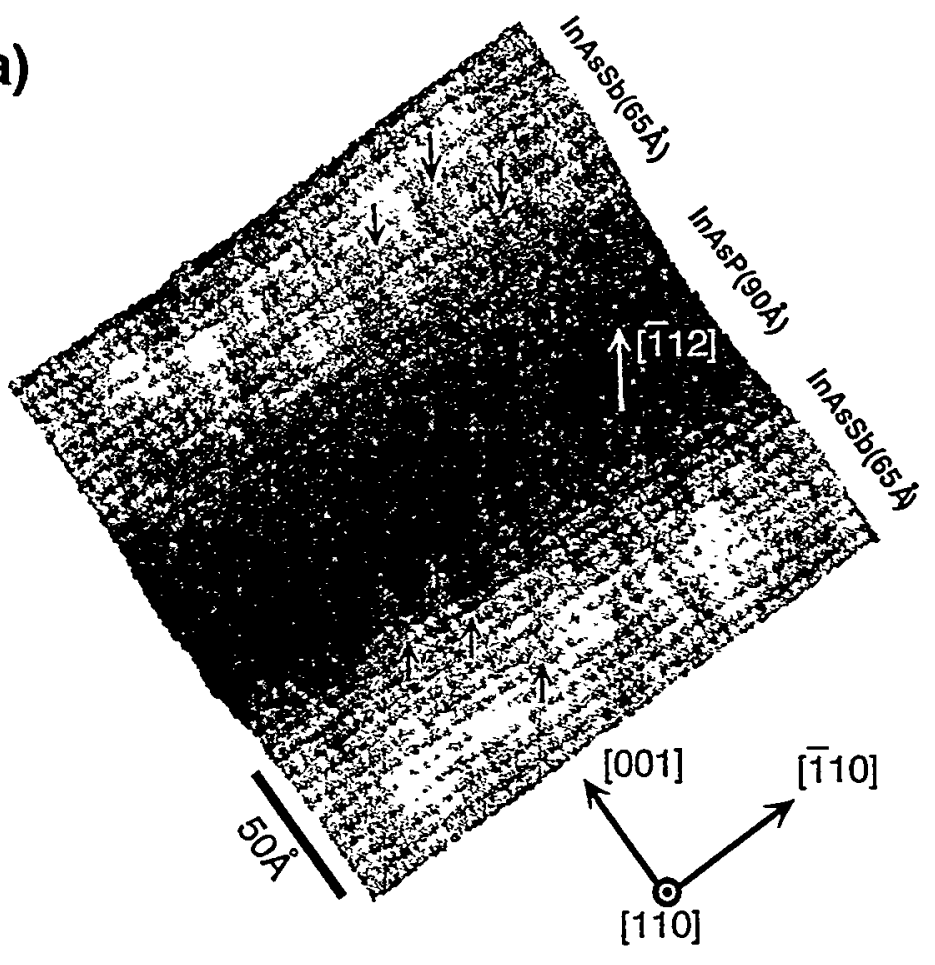

(b)

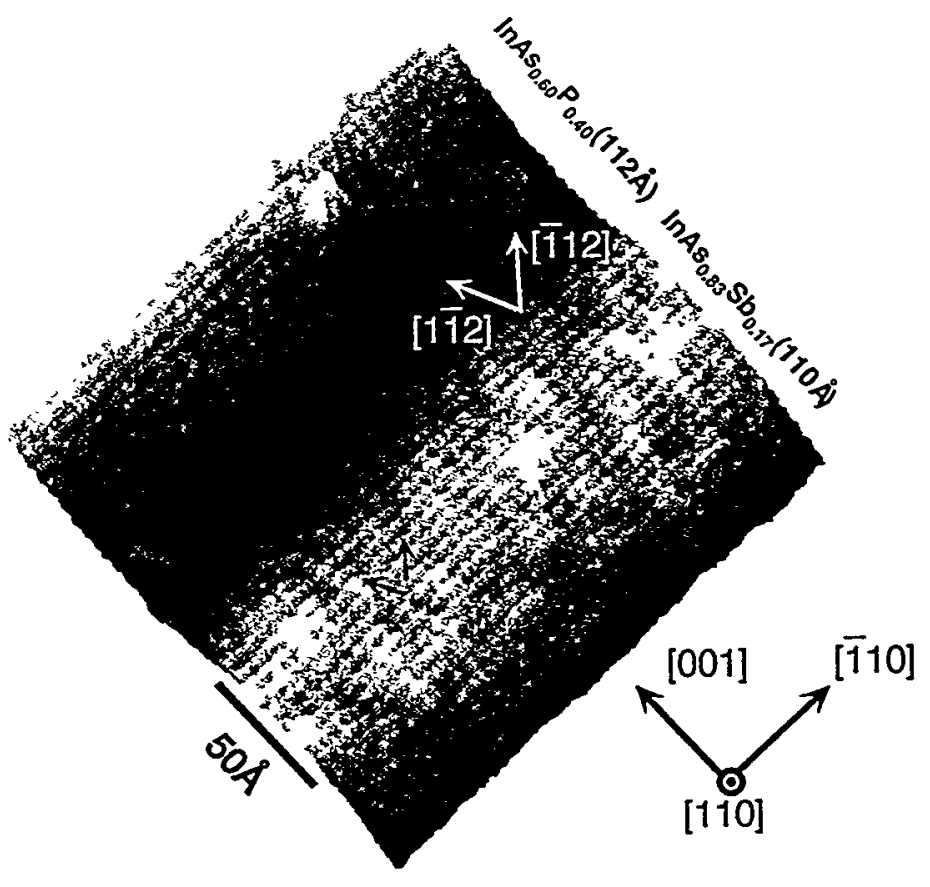

Figure 2

S. L. Zuo et al. 
(a) $\ln A s_{0.87} S b_{0.13}(65 A)$

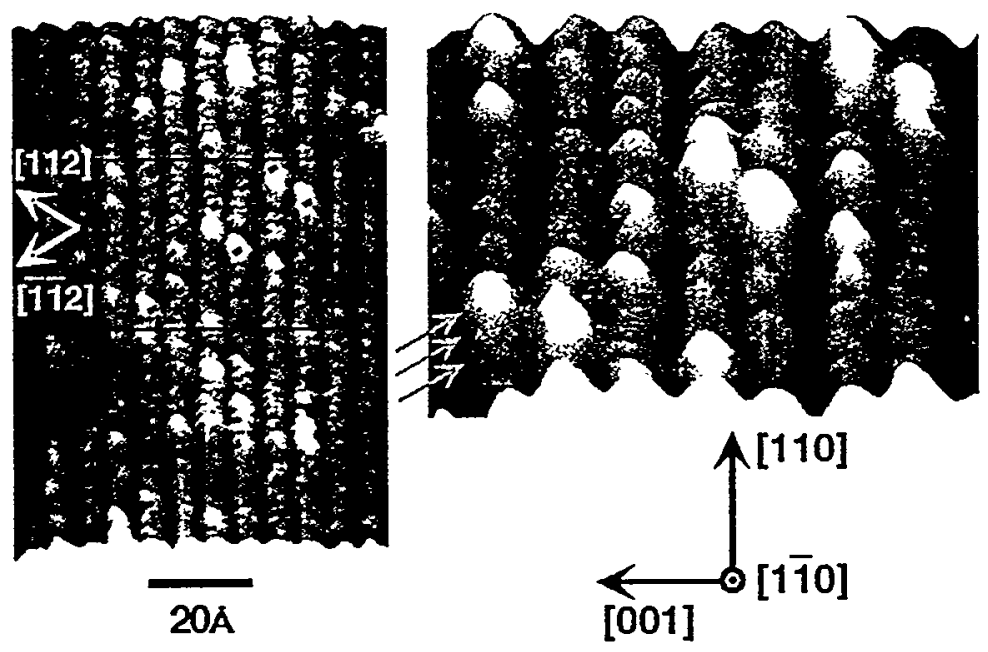

(b)

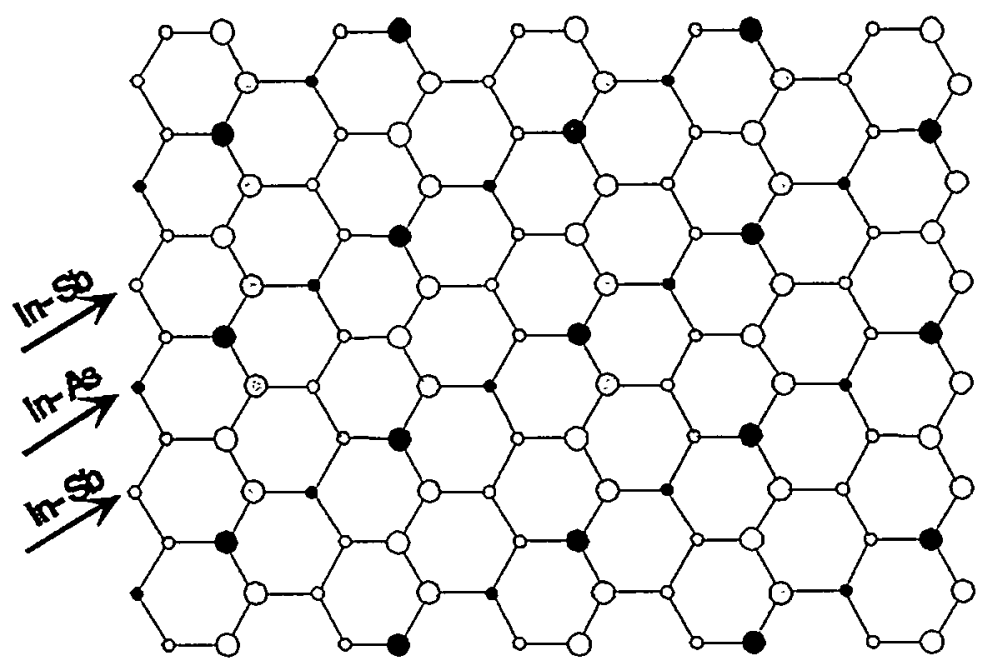

- Top and second layer As atoms

O 0 Top and second layer $\mathrm{Sb}$ atoms

O Top and second layer In atoms

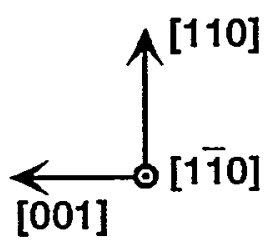

Figure 3

S. L. Zuo et al. 